ARTICLE

https://doi.org/10.1057/s41599-020-0463-y

\title{
OPEN
}

\section{Plastic pigs and public secrets in translational neonatology in Denmark}

Mie S. Dam (10 ${ }^{1 凶}$, Per T. Sangild (10) ${ }^{2,3,4} \&$ Mette N. Svendsen (i) ${ }^{1}$

\begin{abstract}
This paper explores how a translational research platform in Denmark uses piglets as infant models. Drawing on meanings of "public" as "open" and "visible," we track how researchers and clinicians together and separately turn research piglets and premature infants into both public and un-public beings in laboratory and clinical settings. In these complex multispecies relationships, researchers and clinicians alike create and retain certain "zones of unknowing" in which intimate cross-species care relations are fostered. While critical social scientists call for greater public recognition of animals in accounts of human health, our study demonstrates that "zones of unknowing" enable the involved professionals to care simultaneously for neonatal beings and the greater public good. To account for the efforts involved in contributing to the greater public good, we introduce the term "publication work." We argue that publication work relies as much on porosity between species and spaces as on actively drawing boundaries between species and between public and private spaces. Plastic pigs and public secrets are crucial to realise the ambition of more-than-human public health.
\end{abstract}

\footnotetext{
${ }^{1}$ Centre for Medical Science and Technology Studies, Department of Public Health, University of Copenhagen, Copenhagen, Denmark. ${ }^{2}$ Department of Comparative Pediatrics and Nutrition, Faculty of Health and Medical Sciences, University of Copenhagen, Copenhagen, Denmark. ${ }^{3}$ Department of Neonatology, Rigshospitalet, Copenhagen, Denmark. ${ }^{4}$ Department of Pediatrics, Odense University Hospital, Odense, Denmark. ${ }^{\circledR e m a i l: ~ m d a @ s u n d . k u . d k ~}$
} 


\section{Introduction}

- he extensive use of animals in biomedical experimentation has allowed better understanding of basic biology, disease mechanisms, and development of new medical interventions. During the last 20 years, the process of turning animalbased biomedical knowledge into human health has developed into a rapidly growing biomedical subfield termed "translational medicine" or "translational research" (Marincola, 2003; Curry, 2008). The emergence of research that identifies as "translational" is informed by a global trend in research politics linking basic animal science to the public good of human health and to public missions of innovation, economic growth, and international competitiveness (Curry, 2008). In Denmark, as in other European countries and the US, funding agencies and governmental institutions have increasingly turned their attention to the process of "translation" between bench and bedside (Cooper, 2012). Despite this renewed political focus on the connections between animal experimentation and human healthcare, the central role of animal models in translational research (Friese and Latimer, 2019) is not reflected in public accounts regarding medicine and public health more broadly. Biomedical publications consistently leave out the life, suffering and death of research animals (Sharp, 2014, 2019) and both in public health science textbooks and in public communication on health, research animals are mostly invisible (Rock et al., 2014; Svendsen, 2017).

The increasing attention to the absence of animals in public accounts of human health has spurred a call for post-human explorations of how a given "human public" relies on other forms of life (Friese and Nuyts, 2017; Svendsen, 2017), and how public health, which tends to be equated with human health (Rock et al., 2014), can be approached as a shared condition of human and animal populations (Leonelli et al., 2014; Kirk, 2016; Cohn and Lynch, 2017; Hinchliffe et al., 2018; Friese, 2019; Friese and Latimer, 2019). Responding to this call for a more-than-human public health, we explore ethnographically the production of intimate and uneven relations across species and spaces that potentialise research piglets (Svendsen and Koch, 2013) as models for premature infants in translational neonatology research. Paradoxically, maybe, our ethnography demonstrates that the translational potential of the research piglets rests partly on their un-public status. The invisibility of research piglets in public spaces creates possibilities for interdisciplinary collaboration between laboratory and clinic and for intimate cross-species care practices, which enhance the piglet's value for public health and embody its belonging in this public. Recognising this potentiality of the research piglets' "un-publicness" prompts us to ask: How does the invisibility and un-public status of research piglets generate health for human infants? What is the relationship between visibility and invisibility in carrying out translational research across species and spaces?

To delve into to the relational aspects of these questions, we engage the concept of "healthy publics" (Hinchliffe et al., 2018). This concept shifts the focus of public health away from human target populations, towards a greater recognition of the heterogeneous and fragile collectives (of humans as well as nonhumans) that contribute to health and well-being. Moreover, the concept of healthy publics enables us to investigate the complex interrelationship between public and un-public beings in translational research.

According to the Oxford English Dictionary, being "public" can be defined as being "open to general observation, view, or knowledge; existing, performed, or carried out without concealment, so that all may see or hear" (Oxford English Dictionary, 2019). These meanings of visibility and openness are closely associated with information, equity and societal trust; terms that bear positive connotations in modern liberal democracies
(Reardon, 2017). On the contrary, concealment, invisibility and secrecy are left with negative associations (Birchall, 2011) of suppression, exploitation and antidemocratic governance. In contemporary scholarship on science-society relations, openness and visibility, often articulated as transparency, have become ubiquitously tied to good science governance, public legitimacy, and public trust (McLeod and Hobson-West, 2016). As Sheila Jasanoff aptly observes, "it is almost an article of faith that openness is essential both for the advancement of science and for its beneficial interaction with society" (Jasanoff, 2006, p. 1). Yet, in practice, Jasanoff adds, openness in science is almost always limited and traded off against other social values (Jasanoff, 2006). This is the case in the field of animal experimentation, which has a long history of public controversies (Asdal, 2008). Here, animal researchers apply secrecy and closed doors as ways to protect themselves from public stigma and animal activism (Birke et al., 2007), and "selective openness" (Holmberg and Ideland, 2010) serves as a tool for animal researchers to balance ideals of openness against fears of public misunderstandings. In our case of translational neonatology research in Denmark, the relationship between animal science and the public outside the animal laboratory was not a strong concern among the researchers and clinicians we worked with. What did occupy them, however, was how to turn their practices into (human) health and good lives; an endeavour, which involved navigating invisibility and visibility. In the following, we take the public invisibility of the research piglets as a starting point for unravelling how practices of visibility and invisibility contribute to the generation of healthy publics in the field of translational neonatology.

To investigate this intertwinement of visibility and invisibility, we bring our more-than-human approach to public health into conversation with Poul Geissler's work on the anthropology of unknowing. He refers to Michael Taussig's central argument that unknowing relates to "that what is known but must not be articulated in a given societal arrangement" (Geissler, 2013, p. 15) and that "public secrets" (Taussig, 1999) are constitutive of social order in that they make domination unspoken, and silence critique and resistance. Inspired by Taussig's work on the political importance of unknowing, Geissler (2013) explores the contribution of unknowing to public health research-a field that, as Geissler highlights "pursues epistemic and social transformation, amelioration and justice" (Geissler, 2013, p. 16). He finds that in public health research projects, unknowing plays a crucial role in linking actors and institutions, and he argues that social science needs to pay attention to unknowing as a practice. Likewise, Lochlann S. Jain (2010) uncovers how the emphasis on future thinking, hope, and progress in randomised controlled trials in oncology results in "ghosting" of patient lives, suffering and deaths. We take orientation from these studies in tracing how making publicly unknown the suffering and death involved in translational neonatology research is decisive to the efforts put into creating healthy publics and striving for good citizen lives. Crucially, we argue, practices performed behind the closed doors of the publicly financed pig laboratory is not just cruel experiments based on modernist ideas of human exceptionalism. Rather, in the pig laboratory as well as in the human neonatal intensive care unit (NICU), practices of unknowing enable and guard private spaces of care and moral deliberation that constantly challenge and transgress the moral boundaries between experimental animal and human patient.

We begin by presenting the empirical field and our study of translational neonatology. Ethnographic descriptions of entering the publicly unknown space of animal experimentation provide the analytical starting point for the first part of the analysis. Here we direct attention to the ongoing relational work between the 
research piglets and the researchers who work to turn them into models of premature infants that can be represented as graphs and figures in scientific conferences and publications. This leads us to argue that the translational value of research piglets is bound to both their un-publicness and their relational and material plasticity. Next, we enter the human NICU and show how-also-the identity of a premature infant at the margins of life is in some respects plastic and un-public. By juxtaposing the care practices in the NICU and in the animal laboratory, we unsettle the moral hierarchy between pigs and humans, and track how researchers and clinicians turn piglets and infants into public and un-public beings in different contexts. This unusual juxtaposition of research animals and human infants unfolds the "publication work" entailed in forming (human) healthy publics. Etymologically, publication refers to "the act of making publicly known." Our concept of "publication work" builds on this meaning, yet illuminates that publication also intrinsically involves acts of unknowing.

\section{Studying translational neonatology in Denmark}

As one of the Nordic countries, Denmark is characterised by a market economy existing alongside a strong welfare system, including universal healthcare. Among Danes, there is a strong trust in public institutions and most citizens do not distinguish between state, nation, and people. In this world, the "public" constitutes a collective, which encompasses both state institutions and citizens.

In this country, as elsewhere, the national infant mortality rate is acknowledged as a crucial indicator reflecting the level of progress and welfare of a country. Modern liberal democracies invest heavily in providing and optimising intensive healthcare for weak newborn infants. In the Danish NICUs, human infants survive each day due to advanced medical technology and the skilled work of highly specialised doctors and nurses; a public investment, which testifies to a cultural understanding of the newborn human infant as a "sacred" and "untouchable" being holding intrinsic value.

The Danish welfare state also plays a key role in regulating and coordinating the Danish pork production. However, the same efforts are not put into survival within this field. In Danish piggeries, $9 \%$ of all newborn piglets die every day $(\sim 10,000)$ due to immaturity and lack of teats to accommodate the entire litter of piglets (Andersen et al., 2011). Bred for meat consumption, the Danish farm piglet holds almost no intrinsic value in Danish society. Approximately 30 million pigs are produced each year in industrial farms-almost five times the Danish population of $<6$ million people. In the capacity of export goods, Danish pork is often publicly depicted as a crucial resource for the country. Although many Danes have never visited a mass production farm or a slaughterhouse, photos of pigs behind bars and carcasses ready for shipment constitute a well-rehearsed reference point in public discussions of agriculture and export. Pigs are best known as a readily available resource for the national public, and the economic value of pork, as well as the downside of its polluting traces in Danish waters and soil, are frequent topics in public debate.

Danish pork export success is based on breeding pigs with an extra rib, leaner meat, and an increasing number of piglets per litter. This breeding programme relies on decades of close collaborations between the meat production industry and Danish veterinary science. Through this relationship, Danish veterinary science has been in a unique position to mobilise the country's extraordinary expertise on pork in developing pig models in biomedical research (Svendsen, 2016). Also internationally, the close proximity between pigs and humans in terms of genetics, organ size, and physiology have, in medical research, turned pigs into popular models of many different human conditions (Miller and Ullrey, 1987; Kuzmuk and Schook, 2011; Groenen et al., 2012; Swindle et al., 2012). In a Danish context, the public position of the pig as first and foremost an important production animal has led to the use of pigs in biomedical research being uncontroversial, politically as well as publicly.

Biomedical research in the field of translational neonatology brings together the highly valued hospitalised infant and the expendable farm piglet. In an animal laboratory at the veterinary campus at the University of Copenhagen, a group of animal researchers use Danish piglets, which otherwise would have been nurtured for pork, as their primary animal model for premature infants at risk of life-threatening gastrointestinal conditions such as the inflammatory bowel disease necrotising enterocolitis (NEC) (Sangild et al., 2014). NEC is a common cause of death in premature infants and thus a much-dreaded disease in NICUs around the world. The disease has, unfortunately, featured as a prominent problem within neonatal care since the advent of neonatal intensive care in the 1960s and as a hindrance, therefore, to the related improved survival of the smallest infants (Neu and Walker, 2011). Thus, technological developments in neonatal care and the strong imperative to save the lives of preterm infants constitute the background for developing the preterm pig model. Owing to "close similarities with preterm infants in body size, organ development, and many clinical features" (Sangild et al., 2014, p. 4713), the Copenhagen group argues that the preterm pig model holds a greater translational potential than for instance rodent models. To the researchers, the preterm pig may also provide a sensitive model for weak farm piglets and they maintain that they "care about piglets as piglets and not just as infant models."

In the experimental setup that constitutes the preterm pig model, a pregnant sow, brought to the pig facility from a pig farm outside Copenhagen, undergoes a caesarean section 10 to 12 days before the sow is due. Supervised by their professor, a group of veterinarian students take turns making incisions in the belly of the sow. Washed, shaved and covered with a green surgical towel, the sow looks just like a (human) patient, but as soon as the litter of $\sim 20$ slippery little piglets has left her womb, the sow is euthanized and discarded. Researchers and animal technicians are focusing their efforts on making the piglets survive their preterm birth, thus translating them from (unborn) pork to fragile paediatric model animals "imbued with potential for human health" (Svendsen and Koch, 2013, p. 118). The piglets are quickly and carefully placed in heated and oxygenated incubators and for the following five to 26 days fed different combinations of enteral (oral) and parenteral (via the blood stream) nutrition (see Fig. 1).

The animal research group's experimental studies on preterm piglets show consistently that bovine colostrum, the first milk the cow produces after giving birth, significantly reduces the risk of NEC compared to infant formula and possibly also compared to human donor milk (Jensen et al., 2013; Støy et al., 2014; Shen et al., 2015; Rasmussen et al., 2016). Scientific papers from the research group always explicitly underscore the translational potential for compromised human infants. However, despite $>10$ years of publication of scientific articles based on the results from the preterm pig model, the team comes to the conclusion that the evidence published in these scientific journals does not all by itself reach the clinic. The director of the pig laboratory, Per T. Sangild who is the second author of this article, therefore initiates a collaboration with central clinical and industrial partners to translate pig-based research on bovine colostrum into the next stage of clinical studies. In December 2012, the Danish Council for Strategic Research, together with collaborating industries, grants 60 million DKK (Danish Kroner) to the NEOMUNE Centre (2012-2018) headed by 


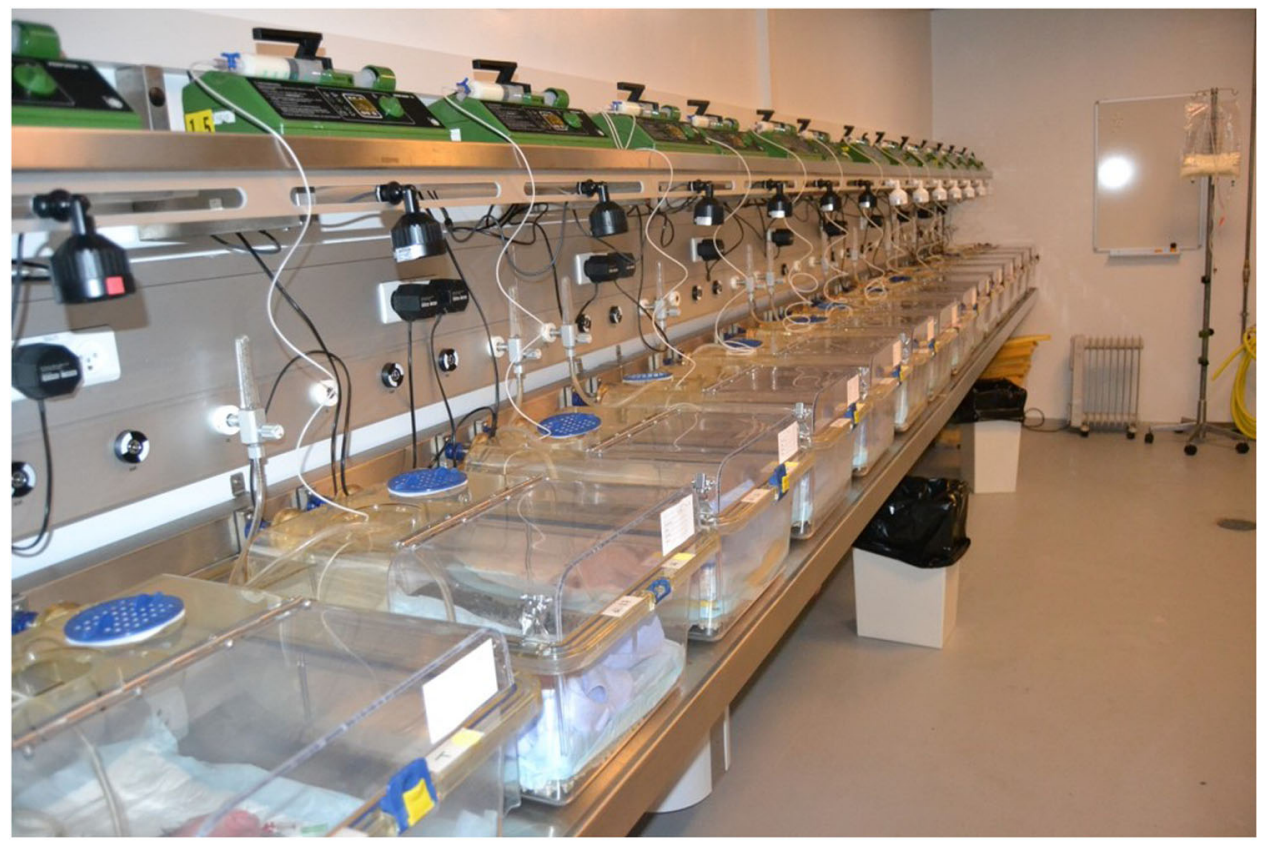

Fig. 1 The preterm pig laboratory. Piglets installed in incubator-like boxes and connected to feeding machines (Photo by Mie S. Dam March 2013).

Per Sangild. NEOMUNE Centre is a university-initiated research platform primarily based on tax money, which aims to improve clinical care of newborn infants, particular those born prematurely or with developmental problems (NEOMUNE Centre, 2019). With this grant, the Danish Council for Strategic Research aims to support public-private research collaborations "organised to meet the challenges facing Danish society" (Danish Council for Strategic Research, 2013). By enroling NICUs and the infant formula industry, the NEOMUNE Centre has succeeded into connecting their translational ambition with the public mission of improving clinical care for newborn infants.

In 2013, the NICU at Copenhagen University Hospital was the first clinic in which a bovine colostrum study was initiated ( $\mathrm{Li}$ et al., 2017; Juhl et al., 2018). The NICU is the largest and the most specialised in Denmark and provides intensive care and treatment to premature newborns (between gestational week 23 and 37) from all over the country. Since its establishment 50 years ago, the Copenhagen NICU has maintained a strong tradition for clinical research and the personnel are highly experienced in clinical research on infants. Thus, the Copenhagen NICU is an appreciated and indispensable partner in NEOMUNE. Yet, the NEOMUNE partners perceive the inter-species translation from piglet to infant as potentially controversial and sensitive and a social science work team is included in NEOMUNE to investigate the ethical aspects of the translational processes across piglets in the laboratory and infants in the NICU.

The first author Mie S. Dam has carried out her Ph.D studies in this work team supervised by the second author, Per Sangild, heading the NEOMUNE Centre, and the third author Mette N. Svendsen, who headed the social science work team and has conducted ethnographic research in experimental and clinical neonatology since 2009. In co-authoring academic publications (Dam et al., 2017; Dam et al., 2018), the three of us seek to make visible the critically engaged dialogue between social science and natural science (Prainsack et al., 2010) that has enabled us to explore inter-species translation in Danish neonatology. The work presented in this paper results from our common engagement in NEOMUNE drawing primarily on Mie's fieldwork activities. As a natural scientist, Per has corrected and nuanced the biomedical content and asked for clarification when the social scientific analysis did not make sense to him. In this way, his questions and comments spurred new analytical reflections and clarity. Danish research ethics regulations do not require ethics approval for qualitative interview and observation studies. According to Danish law, the study was approved by the Data Protection Authorities (Datatilsynet).

From January 2013 to June 2014, Mie participated in NEOMUNE-related activities taking place in and around the preterm pig laboratory. Besides six intense weeks of participation when experimental studies were running in the pig laboratory, she passed the obligatory laboratory animal science course, participated in monthly management group meetings, took part in fortnightly team meetings, travelled with the biomedical researchers to conferences, and followed the piglets and the researchers across experimental spaces. Concurrently, Mie and Mette interviewed researchers involved in the pig studies (seven interviews) and the NEOMUNE steering group members (seven interviews). Between July 2013 and January 2014, Mie followed nurses and doctors in their clinical work life in the NICU at Copenhagen University Hospital, where she observed the practical preparations for the first clinical colostrum study and conducted interviews with parents to learn about their experiences and expectations in relation to feeding bovine colostrum to premature infants (14 interviews).

Moving between the connected empirical activities and sites of translational neonatology has enabled us to grasp the relations across species (piglets; and humans-both infants and researchers) and spaces (laboratory, clinic, conference rooms) that contribute to the formation of healthy publics in the field of translational neonatology. In observing and participating in "more than human encounters" (Lien, 2015), our ethnography was not only multisited (Marcus, 1995) but also multispecies (Kirksey and Helmreich, 2010). Now, let us step into the preterm pig laboratory.

\section{Caring for pigs and public health in the private space of the animal laboratory}

One Monday morning in March 2013, Mie arrived in the preterm pig laboratory at the University of Copenhagen to participate in a 
five-day experiment. At that time, she had just received her Master's degree in public health, and had had no idea that a place like the preterm pig laboratory existed. She had indeed never considered piglets in an experimental laboratory to belong to the field of public health. However, after the first intense week in the animal lab, she was overwhelmed by feelings of ambivalence. It had been fascinating to watch biomedical researchers prepare a sow for a caesarean section, and to observe the tiny piglets being gently fitted with feeding tubes and carefully installed in incubator-like boxes, before-by the end of the experimental week-being euthanised, and their organs turned into standardised biological samples. However, during the long hours in the animal laboratory, Mie could not help asking herself, "What am I doing here? What shall I look for? How come that I, who take an interest in core aspects of public health such as "people," "society," "health and illness," end up watching insignificant animals literally isolated from "the real world" behind the walls of the laboratory?" Mie was eager to turn her attention away from the research piglets and towards the obviously ethically and politically loaded activities of testing new nutritional regimes in human infants at a renowned public university hospital. Likewise, Mette recounted that she had also had similar experiences when she initiated her first research project on pig models in 2009. The notion of the pig as simply a resource for humans, as just meat, penetrated not only Mette and Mie's own initial experiences in the pig laboratory, but also the reactions of their colleagues at the Department of Public Health when they talked about their pig research. In these conversations, it all seemed very simple, "Kill the pigs, save the babies. Over and out!"

In her classroom analysis of British science and technology students and their reluctance to care for radiation-damaged insects in the face of the human tragedy of the Chernobyl disaster, Astrid Schrader (2015) contends that to her students, caring for insects would come at the cost of caring for humans and thus erase the ordained order of things and beings. Similarly, in the face of the overwhelmingly sick premature infants, whom the pig studies were aimed to save, Mette and Mie felt awkward to extend their empathy and engagement as public health researchers to the piglets.

From conversations with clinically educated NEOMUNE researchers Mette and Mie learned that they were not the only ones who considered the pig an unusual research subject. Medical doctors and human nutritionists had likewise been wondering how they ended up working with pigs. Rasmus, a medical Ph.D student, recounted how working in the laboratory with the piglets as paediatric models became a "point of inversion" for him. Suddenly, he understood that most of the physiology and pathology he had crammed in medical school was actually based on animal studies. In an interview Rasmus reflected, "The textbooks sometimes did say "this and this about the brain or the kidney is based on studies in mice and rats", but somehow I never took it in that what we know about the human is actually one big puzzle pieced together from many different species in many different situations." In an effort to respond to this situation and make clinicians see and acknowledge the translational potential of pig research, Per employed his position as director of NEOMUNE to embark on a new translational strategy, which he referred to as "visiting each other's houses" (see Fig. 2). This translational strategy built on close exchange of personnel between "the house" of the pig laboratory and "the house" of the NICU.

In the NEOMUNE pig studies, animal scientists and medical doctors from the Copenhagen NICU worked side by side. Often visitors from other NEOMUNE work teams were also present: international neonatologists, industry collaborators, graduate students from other Danish NICUs, or from the NEOMUNE mice studies. In this way, Per worked consciously to make visible

\section{Translational Pediatric Research}

How to get from bench to bedside - and beyond?

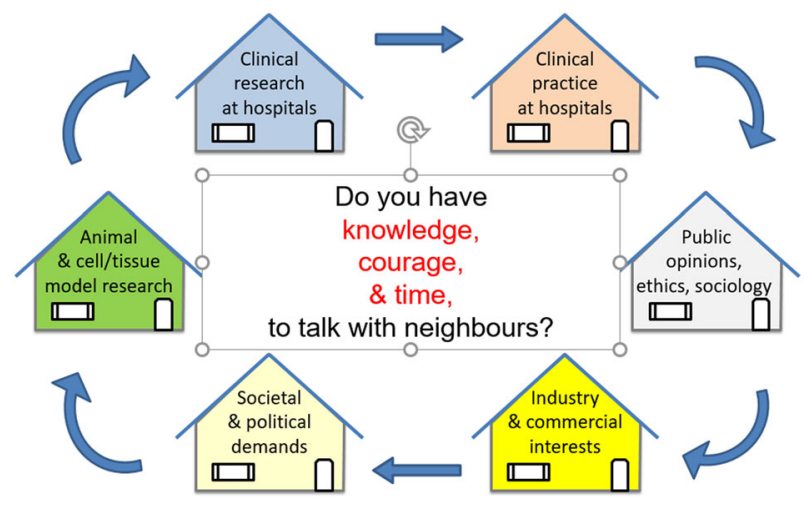

Fig. 2 "Visiting each other's houses". This figure is produced by Per Sangild. He often presented the figure at peadiatric conferences and NEOMUNE meetings to illustrate the translational strategy of NEOMUNE.

both the animal facility and the piglets that populate this space. However, he did so without turning the pig laboratory into a publicly known space "open to general observation" (Oxford English Dictionary, 2019). Rather, as the terminology of "visitors" and "houses" implies, he included the heterogeneous partners involved in the translational research endeavour of NEOMUNE in the private space, the household, of the pig laboratory. In NEOMUNE, piglets and animal laboratory thus became a platform for experiments on not only how bovine colostrum affects the guts of premature pigs, but also on how collaborative encounters affect the translational path (Dam et al., 2018).

\section{The plasticity of pigs and professionals}

As part of the translational strategy, the interdisciplinary research team also allowed Mette and Mie, the only two social scientists in NEOMUNE, to take an active part in almost all of their activities in the pig laboratory. Despite their initial reservations, Mette and Mie did "begin to care about" (Puig de la Bellacasa, 2015; Schrader, 2015; Friese, 2019) the piglets. The kind of collaboration they became part of is well captured by Joanna Latimer's concept of "being alongside", which refers to "cooperating with one another, even working together, but not necessarily to the same ends" (Latimer, 2013, p. 80). In this form of relationship, in which togetherness coexists with difference, Mette and Mie experienced that the piglets in the laboratory space changed the way they related to the pig in public health. Instead of feeling strange about fieldwork among research piglets, they felt the urge to cover up the piglets' tiny bodies with their little cloths before closing the door to the animal laboratory after a late-night feeding session; they were deeply engaged in the researchers' dilemma of whether or not to euthanise a weak and suffering piglet; and they felt the adrenalin-rush when the researchers trusted them to take care of the piglets and thereby the results of the study. Once, Mie even found herself kissing the downy forehead of "little R," a piglet that she had worried about during the night as he would not eat and felt limp. Being alone with the piglets she sensed how making her body available (Lien, 2015, p. 16) to them was constitutive of strong feelings of relatedness. As other researchers have also pointed out, care in science fosters intimate relations, which shape both the data holder and the scientific quality of data (Friese, 2013; Pinel et al., 2020). The piglets were far from being just data, just as Mie was far from being just a data manager. During the experimental weeks, such experiences provided us with an understanding not only of the intimate entanglements 
that evolved between the human researchers and the piglets (Friese, 2019; Sharp, 2019), but also between the medical doctors and animal scientists who worked together in the animal laboratory.

Day and night, animal researchers and medical doctors cared meticulously for each individual piglet. They made regular checkups, treated weak piglets by adjusting the temperature in their incubator, took out a little air from their stomach, and gave them medication to stop their diarrhoea and other infections. This kind of united individual care work was crucial to enable the hypersensitive neonate piglets to survive in the laboratory environment, and was thus absolutely integral to the experimental practices (see Fig. 3). In this way, Mie and Mette's engagement in the pig laboratory taught them that caring about piglets does not come at the cost of caring about infants. Rather, they came to see care for research animals and care for future human patients as a mutual concern (Davies, 2012; Friese, 2013).

In the every day practices of the pig laboratory, the NEOMUNE research team experienced how the urgency of attending to the bodily needs of the hypersensitive piglets united animal researchers, medical doctors, and social scientists in heterogeneous care practices that blurred the boundaries between species and disciplines in translational neonatology (Dam et al., 2018). When the collaborating medical doctors were running studies with the animal researchers in the laboratory, they suggested changes in the laboratory set up based on their clinical experiences, but generally conformed to the norms of the animal laboratory and partly became animal researchers themselves. When treating a compromised piglet the animal researchers came to identify themselves as "mini-neonatologists". Medical doctors and animal researchers, along with the two social scientists, were all ready to care for the piglets almost as parents care for their child (Dam et al., 2017), and in this spatial and social context the premature piglets took on an identity almost as neonate patient (Dam and Svendsen, 2018). These transformations resemble how Karen-Sue Taussig, Klaus Hoeyer and Stefan Helmreich define potentiality as a "genuine plasticity-the capacity to transmute into something completely different" (Taussig et al., 2013, p. 6). The possibility of shaping the piglet through material infrastructures and care work was indeed linked to its potential as a translational model. However, whereas potentiality refers to "that which does not (and may never) exist” (Taussig et al., 2013, p. 3)-for instance the future promise of improved nutrition for human infants in the NICUour research revolved around the present and near future effects of

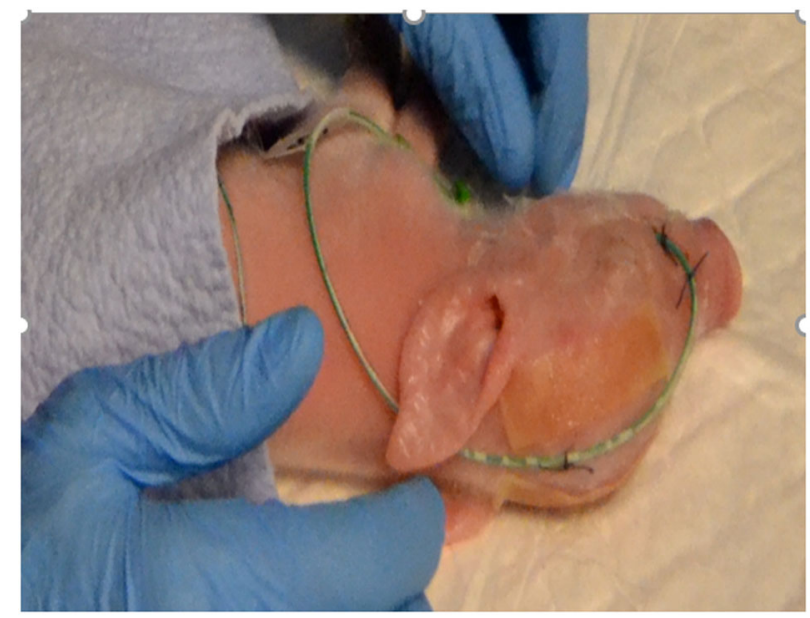

Fig. 3 Individal care in the pig laboratory. A researcher cares for a premature piglet in the pig laboratory. The green line provides the piglet with enteral nutrition (Photo by Mie S. Dam June 2013). the piglets' material and relational plasticity. The plasticity we observed cut across both professionals and piglets and was closely related to the notion of "almost:" From day to day, borders between disciplinary fields blurred and opened a space for professionals to almost become part of another discipline. Likewise, borders between species blurred and opened up space for piglets to become almost human patients. By "visiting each other's houses," professionals were alongside each other (Latimer, 2013) and a strong sense of solidarity-what Per referred to as "the musketeer spirit" of the "big NEOMUNE family,"-emerged across disciplinary and species borders.

In their analysis of translation in biomedicine, Lowe et al., (2019) identify that biomedical researchers are increasingly fostering collaborative relations across laboratory and clinic to align practices of animal and patient care and hereby advance the translatability of their preclinical animal research. However, while the researchers interviewed by Lowe and his colleagues emphasise changes in experimental setup and pharmaceutical agents, we contend that the translational value of establishing the pig laboratory as a "space of encounter" with nonhumans (Johnson, 2015) was first and foremost that it spurred an opening in thought that enabled the research team, including Mette and Mie, to respond more carefully to piglets (See also Bennet, 2010; Haraway, 2008).

By taking on the identity of suffering neonate patients, and, by being accepted by the medical doctors and researchers as having done so, the piglets did at one and the same time appear as "better models" in the eyes of the medical doctors and also encouraged the research team to work even harder to translate the pig-based data into health for human infants. Following these efforts, Mette and Mie noticed how the research team developed their "capacity to read the other" (Clark, 2007, p. 62) and how they compassionately treated the piglets as "respons-able" subjects (Haraway, 2008). We may say that the piglets taught all of us how "practices of knowledge can become practices of care" (Despret, 2004, p. 130). Altogether, we came to engage in an "intimate knowledge practice with an ethical relationship to more-than-human others" (Schrader, 2015, p. 665) in which the position of the piglet as (only) a tool, as well as the position of the infant as the (only) patient shifted slightly (Dam et al., 2018). In the private space of the laboratory, the piglets plastically transformed from farm animals to become almost infants.

This was apparent in the care they received, but also in other ways. In conversations among researchers in the laboratory and between Mette and Mie when discussing fieldwork experiences, the piglets were often unintentionally referred to as "infants;" a slip of the tongue, which expressed that the piglets were not only passive "model" receptors of procedures and care-through their relational and material plasticity they brought about the formation of technical, affectionate, and fleshly cross-species relationships. These frail premature piglets profoundly paved the way for translation by enabling medical doctors and animal researchers to experience a joint ownership of the pig studies and a joint responsibility for introducing bovine colostrum into the clinic.

Just as the medical Ph.D student Rasmus explained how his work with piglets as neonate models had changed his way of looking at the relationship between human and animal health, Mette and Mie's intense experiences in the pig laboratory, in which the eyes of everyone were on the piglets, provided them with a greater understanding of the multispecies relations involved in the health and illness of human and nonhuman animals (Rock, 2013; Rock et al., 2014; Friese and Nuyts, 2017). When leaving the animal laboratory to do fieldwork in other places related to translational neonatology, the "patientised" piglets (Dam and Svendsen, 2018) travelled with Mette and Mie in their minds, and they became highly aware of the 
"unrecognised entanglements" (Tsing, 2015, p. 274) between research animals and human health and the ways in which these entanglements were actively unknown in public spaces (Geissler, 2013).

Following the researchers from the pig laboratory at paediatric conferences, Mette and Mie noticed how the NEOMUNE researchers always began the narrative of their research in the human clinic. For instance, they introduced their presentations of pig-based data by showing pictures of newborn human infants along with descriptions of the epidemiology and the clinical consequences of severe and life-threatening conditions such as NEC. These compelling accounts from the clinic were then usually followed by graphs, tables and $p$-values based on quantitative data from the pig studies, providing the medical and natural scientists in the audience with a generic statistical analysis of laboratory results. In these talks, the demanding care work and the biographical "patient lives" of the preterm piglets preceding those results, were always left out (Svendsen, 2020). Participating in these events, Mette and Mie could not help seeing the piglets as "ghosted" lives (Jain, 2010).

However, in discussing this with Per and the research team, Mette and Mie came to understand that this way of unknowing the life, suffering, and death of the piglets was not motivated by a wish to keep the laboratory practices secret. Rather, the researchers acted in accordance with generally accepted scientific norms (in the natural and the medical sciences) in which their enormous care work in the animal laboratory does not count as science and in which their efforts to understand and treat the clinical conditions of each individual piglet may even appear as compromising scientific ideals of standardisation (Dam and Svendsen, 2018). Only as data, bearing no trace of the piglet's "patient identity", could the pig research be published and acknowledged in scientific conferences and papers (Svendsen, 2020). By framing their research through references to infant patients and adhering to statistical results based on pigs, the biomedical researchers aimed for publications, which would live up to the scientific requirements of their field and concomitantly demonstrate the value of their animal research to clinical scientists and to funding agencies stressing "societal relevance." While the researchers' felt a strong ethical responsibility for translation, their efforts also resulted in their ghosting piglet lives and unknowing fleshly details about them. Here, piglet plasticity enabled fleshly animals to turn into standardised knowledge.

Altogether, ethnographic fieldwork in the pig laboratory and in conference rooms showed that translational neonatology research is underpinned by complex practices of knowing and unknowing, a kind of ethical boundary work (Wainwright et al., 2006), which we conceptualise as "publication work." With this concept, we seek to capture the work involved in making translational animal science publicly available. Susan L. Star and James R. Griesemer originally pointed to scientific papers as central means of translation between different social worlds as scientific papers' "structure is common enough to more than one world to make them recognisable" (Star and Griesemer, 1989, p. 393). Our ethnographic case adds to this insight by unfolding that publication work in translational research is conditioned on the creation of private spaces for intimate cross-species care relations and on protecting such private spaces of care from general observation. That is, translational knowledge productions (such as scientific papers) rely on knowing the animal in ways that momentarily dissolve the moral and existential borders between research animal and human patient, and on unknowing this relationship by absorbing the individual animal into statistical representations of laboratory results, and presenting research animals as standardised and unproblematic tools for human health and survival. In skillfully creating these boundaries between knowing and unknowing, the involved researchers strived to act ethically and realise the ambition of healthy publics.

\section{The un-public infants at the margins of life}

The ethnographic fieldwork in the Copenhagen NICU added yet another layer to our conceptualisation of publication work in translational research. On a Friday afternoon in June 2013 Mie followed Doctor Jonas into the room of a severely ill child, Mattie. He was intubated and connected to a tangle of tubes and electrodes. As Jonas and Mie stood by the incubator, Jonas said that he was no longer convinced that it was ethically responsible to continue Mattie's treatment. He then repeated what he had presented at the medical conference several times during the week: Mattie would not be alive if it were not for resuscitation at birth and the maximum level of intensive care he had subsequently been receiving. As Jonas talked, Mattie's nurse approached and Jonas introduced Mie saying, "This is Mie. She has nothing else to do on a Friday night." They all three laughed quietly and continued chatting a bit about where to go on a Friday night these days. As the nurse then assisted Jonas in the difficult task of providing Mattie with a new intravenous line, Jonas, highly concentrated, asked Mie to bring him a syringe, to cut a piece of gauze, and hand him a piece of cotton, and Mie felt happy for the rare occasion of being asked to assist. While active participation had been key to her fieldwork in the pig laboratory, doing fieldwork in the NICU, where infants were at the margins of life and their parents went through the crisis of having a severely ill child and being confronted with the unbearable risk of losing their newborn child, was mostly characterised by an intense kind of attentive and reflective observation. Mette and Mie had both experienced their days of fieldwork in the NICU as emotionally burdensome and they had ascribed their feelings to being a "natural reaction" to the severe situation of the premature child. However, despite of the presence of a severely ill child, that Friday night the atmosphere in the room reminded Mie of the collegial cosiness she had experienced so many times in the pig laboratory. Also, Mattie's belly, swollen and bluish, resembled the many cases of NEC she had observed in the pig laboratory and Mie could not help thinking, "If Mattie was a piglet he would never have had to suffer in this way." In that moment, withdrawing Mattie's treatment seemed as the only right thing to do.

About $1 \mathrm{~h}$ later Mie was back in Mattie's room, this time sitting on a chair by his parents. Owing to the official NICU policy of family-centred care, the parents had a bed next to the incubator of their child and they were routinely involved in daily care, as well as in medical decisions. This Friday evening Mattie's mother sat on the bed with her loose blouse turned aside to make room for a breast pump that with a rhythmic sound worked to extract breast milk for her son. Sitting next to Mie, Doctor Jonas initiated the difficult task of informing the parents about the severity of Mattie's situation, "We have reached the point where we need to consider what we can do for Mattie. I have to tell you that he is critically ill." As Mie now looked towards Mattie's incubator she suddenly noticed that pictures of his siblings decorated the wall. Beneath one picture it said with childish letters, "Welcome to the world, Mattie. We love you!" Mie's throat went dry and she had to hold back her tears as she was overwhelmed by sadness and compassion for Mattie and his family. The atmosphere in the room was now dense with gravity and sorrow. The breast pump was still pumping rhythmically while Jonas spoke softly saying things like, "I am very worried about his brain as well. At some point you will have to decide if you want to continue. Your life will change, if Mattie survives. He will not be able to eat, talk or walk. You have to think about what you consider to be a worthy life and when you do that you will have to think about your other 
children as well. However, you're not alone. It's my responsibility too." Mattie's mother started to move. Desperately fumbling she freed herself from the breast pump and threw herself into the arms her husband. "We will give you some peace," Jonas said, and Jonas and Mie left.

Even though this situation appeared extremely intimate and private, the presence of Mattie's parents in the hospital room did also connect him to the world outside the clinic. As we describe, their presence literally "activated" the pictures on the wall as these suddenly exhibited what Jane Bennet (2010) has termed their "thing-power" in that they provoked affect and together with the other actors in the room enacted Mattie as a unique human infant loved by his parents and siblings. In this situation, comparing Mattie's life, suffering and imminent death to that of an expendable research piglet was completely unthinkable. Hence, the tough case of Mattie powerfully demonstrated how "sociomoral-material" practices shape how we understand and ascribe value to living beings (Svendsen, 2011; Svendsen, 2015), demonstrating also that the ways in which the premature infants can be known depend on the situation. Like the piglets, the premature infants were in some respects relationally and materially plastic.

Paradoxically however, the presence of Mattie's loving parents confirmed that it takes more than mere survival to live a life outside the hospital as part of family and society and it became painfully visible how even human survival is not always the ultimate (public health) goal. From observing health professionals in their daily work in the NICU, Mette and Mie knew that the medical doctors agreed that keeping highly compromised infants alive "just because we can" was not always ethically sound. Despite advanced technological possibilities for saving premature infants, the doctors maintained their duty to prevent meaningless suffering, sometimes also referring to the Hippocratic Oath. They insisted on the need "to keep trying to do what we think is right." Bearing in mind that some infants' survival would lead to extremely compromised lives-which would exhaust their parents at the expense of their siblings, and moreover take away resources from other hospitalised infants-doctors strove to prevent this by withdrawing futile treatments (Navne and Svendsen, 2018). Thus, cases like Mattie's spelled out that differentiating and prioritising human lives is also part of forming human healthy publics. Monday morning, Mie received an e-mail addressed to Dr. Jonas and to her. In this e-mail the NICU professor expressed that he supported a decision of withdrawing Mattie's treatment as it was now only prolonging his inevitable graduation towards death. The following day Mattie died.

One week later, Mie was back in the pig laboratory. Confronted with the tiny piglets installed in incubators with the direct purpose of enabling more infants survive in the clinic, she could not help thinking of Mattie and the suffering he had to endure due to the maximum level of intensive care that had kept him alive. However, Mie realised, infants like Mattie were unknown (Geissler, 2013) in the pig laboratory. When the animal researchers reflected on their research, it was the healthy human babies they pictured. During pig experiments, Mie occasionally listened to expressions such as, "If only my work can save a single infant then it's worth it." In a workshop, which Mette and Mie arranged to facilitate a discussion around the ethical aspects of translational research, an experienced post-doctoral researcher reflected, "This morning I saw a poster against using mice in the cosmetics industry. It said "Most mice die because of wrinkles." I thought about this and I realised that for me it makes a huge difference that I work with animals for the sake of the clinic (...) I'd have great difficulties working with animals for cosmetics." Peter, another post-doc in the group smiled as he said in a soft tone of voice, "babiiies!!!"
While Peter was clearly joking by introducing into the conversation the affective value of cute little babies, his comment expressed how interactions between researchers in the laboratory imbued the suffering of the research piglets and the hard work of caring for them with the value of human becoming and with notions of public generativity. In other words, the risk of NEC in premature infants and the need for prevention and cure, formed a legitimate alliance between pig and researcher in order to improve human health. This translational exchange of animal suffering for human health, left no space for infants like Mattie, who, if he had against all odds survived, would not have been able to live what Doctor Jonas referred to as a "worthy life". In the animal laboratory as well as in public presentations of the pigbased research, the preterm human infant could only be known and made visible as a being holding intrinsic worth and potential. In these spaces, the life and worth of the human infant could not be differentiated or plastic. It needed to be static. That is, unknowing practices were not confined to interactions with research animals. The conversation in the workshop-"not working for cosmetics," but for "babiiies"-constituted a form of publication work in translational neonatology, which made particular infants unknown.

Likewise, most mortality measures, such as infant mortality rates, present lives in a static and undifferentiated manner (Fas$\sin , 2016)$. While such measures are recognised as strong indicators of public health, and open to public view and assessment, life-and-death decision-making in the NICU taught us that creating healthy publics entails differentiating human lives.

\section{Conclusion}

This paper has explored the publication work involved in making stories about research piglets and human infants available for public view. We have argued that knowing and unknowing is equally important to publication work. In the animal laboratory as well as in the human NICU, creating and retaining certain "zones of unknowing" (Geissler, 2013) paved the way for particularly complex forms of knowing and caring for neonates. In the private space of the publicly financed pig laboratory, piglets received almost the same meticulous care as hospitalised infants, and plastically adapted to an almost infant patient identity. In navigating this cross-species relationship, the researchers enhanced the chances both of the survival of the piglets during the experiment, and of their translational quality as neonate models. Likewise, in the private space of public hospital rooms, medical doctors carefully deliberated on how best to know and care for infants at the fringes of life, sometimes reaching the difficult decision of withdrawing treatment and letting the infant die. In the borderline situation of differentiating and prioritising human lives, not only the well-being of the individual child, but also the resources of the family and the greater societal collective were taken into consideration. Hence, our ethnography, in which we have entered these un-public spaces of translational neonatology, reminded us of the complexity of caring for liminal beings as part of creating human healthy publics.

Is it so that it takes intimate and embodied experiences to comprehend the complexities and the compromises involved in care practices, which dissolve well-established public categories such as human and animal, life and death? What would change if all of this were made publicly available? While we have no answers to these questions, we want to end this paper by a note on public trust. In the introduction to this paper, we presented the causal linking of transparency and public trust as key trope in science-society literature. Interestingly, Mette and Mie's interaction with researchers and clinicians in spaces that are not open to the public points to alternative ways to comprehend the 
relationship between public trust and (in)visibility. In every aspect of their work, translational researchers and health professionals were not just caring for neonates, they were also caring immensely about living up to the expectations of public trust. Acting within societal frameworks decreeing that animals can be used as tools for human health and that infants born as early as gestation week 23 can be saved, researchers and clinicians did their utmost to do what was best for the (human and animal) beings in their custody, as well as for the societal collective as a whole. The private spaces of care that help to realise the ambition of healthy publics in translational research were created and maintained by public trust and by publicly employed researchers and clinicians striving to honour this trust. The publics were always present in the animal laboratory and the human clinic in which professionals managed commitments to society and the neonates with whom they shared this society. As Jenny Reardon notes in her study of public and private domains in connection to genomics, privateness does not necessarily oppose publicness (Reardon, 2017, p. 167). In the Danish case, ways of knowing piglets and infants in private spaces in, respectively, the animal facility and the human NICU, and subsequently unknowing these beings in public spaces, aimed at doing good for the public. The ethical boundary work on the ground teaches us that knowing and unknowing, public and private, cannot be seen as fixed dichotomous frames; but that in fostering healthy publics, they are continuously being built, delineated and linked anew.

\section{Data availability}

The data generated during this study is not publicly available due to privacy issues.

Received: 20 December 2019; Accepted: 6 April 2020;

Published online: 06 May 2020

\section{References}

Andersen IL, Nævdal E, Bøe KE (2011) Maternal investment, sibling competition, and offspring survival with increasing litter size and parity in pigs (Sus scrofa). Behav Ecol Sociobiol 65(6):1159-1167. https://doi.org/10.1007/ s00265-010-1128-4

Asdal K (2008) Subjected to parliament: experimental medicine and the animal body. Soc Stud Sci 38(6):899-917

Bennet J (2010) Vibrant matter: a political ecology of things. Duke University Press, Durham, NC

Birchall C (2011) Introduction to 'secrecy and transparency': the politics of opacity and openness. Theory Cult Soc 28:7-25

Birke L, Arluke A, Michael M (2007) The sacrifice: How scientific experiments transform animals and people. Purdue University Press, West Lafayette, IN

Clark N (2007) Animal interface: the generosity of domestication. In: Cassidy R, Mullin M (eds) Where the wild things are now: domestication reconsidered. Berg, Oxford, pp. 49-70

Cooper M (2012) The pharmacology of distributed experiment-User-generated drug innovation. Body Soc 18(3-4):18-43

Cohn S, Lynch R (2017) Posthuman perspectives: relevance for a global public health. Crit Public Health 27(3):285-292

Curry SH (2008) Translational science: past, present, and future. Biotechniques 44 (2): $2-8$

Dam MS, Juhl SM, Sangild PT, Svendsen MN (2017) Feeding premature neonates: kinship and species in translational neonatology. Soc Sci Med 179:129-136. https://doi.org/10.1016/j.socscimed.2017.02.039

Dam MS, Sangild PT, Svendsen MN (2018) Translational neonatology research: transformative encounters across species and disciplines. Hist Philos Life Sci 40:21. https://doi.org/10.1007/s40656-018-0185-2

Dam MS, Svendsen MN (2018) Treating Pigs: Balancing standardisation and individual treatments in translational neonatology research. BioSocieties 13 (2):349-367

Danish Council for Strategic Research (2013) http://ufm.dk/forskning-oginnovation/rad-og-udvalg/tidligere-rad-og-udvalg/det-strategiskeforskningsrad/om-radet. Accessed 10 Mar 2013
Davies G (2012) Caring for the multiple and the multitude: assembling animal welfare and enabling ethical critique. Environ Plan D: Soc Space 30 (4):623-638

Despret V (2004) The body we care for: figures of anthropo-zoo-genesis. Body Soc 10(2-3):111-134

Fassin D (2016) The value of life and the worth of lives. In: Han DasV (eds) Living and dying in the contemporary world: a compendium. University of California Press, Oakland CA

Friese C (2013) Realizing potential in translational medicine. Curr Anthropol 54 (7):129-138

Friese C (2019) Intimate entanglements in the animal house: caring for and about mice. Socio Rev 67(2):287-298. https://doi.org/10.1177/0038026119829753

Friese C, Latimer J (2019) Entanglements in health and well-being: working with model organisms in biomedicine and bioscience. Med Anthropol Q 33 (1):120-137. https://doi.org/10.1111/maq.12489

Friese C, Nuyts N (2017) Posthumanist critique and human health: how nonhumans (could) figure in public health research. Crit Public Health 27 (3):303-313

Geissler PW (2013) Public secrets in public health: knowing not to know while making scientific knowledge. Am Ethnol 40(1):13-34

Groenen MA, Archibald AL, Uenishi H et al. (2012) Analyses of pig genomes provide insight into porcine demography and evolution. Nat 491 (7424):393-398

Haraway DJ (2008) When species meet. University of Minnesota, Minnosota

Hinchliffe S, Jackson MA, Wyatt $\mathrm{K}$ et al. (2018) Healthy publics: enabling cultures and environments for health. Palgrave Commun 4(57) https://doi.org/ 10.1057/s41599-018-0113-9

Holmberg T, Ideland M (2010) Secrets and lies: 'Selective openness' in the apparatus of animal experimentation. Public Underst Sci 21(3):354-368

Jain SL (2010) The mortality effect: counting the dead in the cancer trial. Public Cult 22(1):89-117

Jasanoff S (2006) Transparency in public pcience: purposes, reasons, limits. Law Contemp Probl 69:21-45

Jensen ML, Sangild PT, Lykke M et al. (2013) Similar efficacy of human banked milk and bovine colostrum to decrease incidence of necrotizing enterocolitis in preterm piglets. Am J Physiol Regul Integr Comp Physiol 305(1):R4-R12

Johnson ER (2015) Of lobsters, laboratories, and war: animal studies and the temporality of more-than-human encounters. Environ Plan D: Soc Space 33 (2):296-313. https://doi.org/10.1068/d23512

Juhl SM, Ye X, Zhou P, Li Y et al. (2018) Bovine colostrum for preterm infants in the first days of life: a randomized controlled pilot trial. J Pediatr Gastroenterol Nutr 66(3):471-478. https://doi.org/10.1097/MPG.0000000000001774

Kirk RW (2016) Care in a cage: materializing moral economies of animal care in the biomedical Sciences, c. 1945-. In: Bjørkdahl K, Druglitrø T (eds.) Animal housing and human-animal relations: Politics, practices and infrastructures. Routledge Animal Studies Series. Buller H (ed), London and New York, pp. $167-185$

Kirksey SE, Helmreich S (2010) The emergence of multispecies ethnography. Cult Anthropol 25(4):545-576

Kuzmuk KN, Schook LB (2011) Pigs as a model for biomedical sciences. In: Rothschild MF, Ruvinsky A (eds.) The genetics of the pig. Oxfordshire, UK, pp. $426-444$

Latimer J (2013) Being alongside: rethinking relations amongst different kinds. Theory Cult Soc 30:77-104

Leonelli S, Ankeny RA, Nelson NC, Ramsden E (2014) Making organisms model Human behavior: Situated models in North American alcohol research, since 1950. Sci Context 27:485-509

Li Y, Juhl SM, Ye X et al. (2017) A stepwise, pilot study of bovine colostrum to supplement the first enteral feeding in preterm infants (Precolos): Study protocol and initial results. Front Pediatr 5(42):1-9

Lien ME (2015) Becoming salmon. Aquaculture and the domestication of a fish The University of California Press, Oakland

Lowe J, Leonelli S, Davies G (2019) Training to translate: understanding and informing translational animal research in pre-clinical pharmacology. Tecnoscienza 10(2):5-30

Marcus GE (1995) Ethnography in/of the world system: the emergence of multisited ethnography. Annu Rev Anthropol 24(1):95-117

Marincola FM (2003) Translational medicine: a two-way road. J Transl Med https://doi.org/10.1186/1479-5876-1-1

McLeod C, Hobson-West P (2016) Opening up animal research and science-society relations? A thematic analysis of transparency discourses in the United Kingdom. Public Underst Sci 25(7):791-806. https://doi.org/ $10.1177 / 0963662515586320$

Miller ER, Ullrey DE (1987) The pig as a model for human nutrition. Annu Rev Nutr 7(1):361-382

Navne LE, Svendsen MN (2018) Careography: staff experiences of navigating decisions in neonatology in Denmark. Med Anthropol 37(3):253-266. https:// doi.org/10.1080/01459740.2017.1313841 
NEOMUNE Centre (2019) https://neomune.ku.dk/ Accessed 17 Dec 2019

Neu J, Walker WA (2011) Necrotizing enterocolitis. N. Engl J Med 364(3):255-264

Oxford English Dictionary (2019) https://www.oed.com/view/Entry/154052? rskey $=$ K5JBzl\&result $=1$ \&isAdvanced $=$ false\#eid Accessed 17 Dec 2019

Pinel C, Prainsack B, McKevitt C (2020) Caring for data: value creation in a dataintensive research laboratory. Soc Stud Sci. https://doi.org/10.1177/ 030631272090656

Prainsack B, Svendsen MN, Koch L, Ehrich K (2010) How do we collaborate? Social science researchers' experience of multidisciplinarity in biomedical settings. BioSocieties 5:278-286. https://doi.org/10.1057/biosoc.2010.7

Puig de la Bellacasa M (2015) Making time for soil: technoscientific futurity and the pace of care. Soc Stud Sci 45(5):691-716

Rasmussen SO, Martin L, Østergaard MV et al. (2016) Bovine colostrum improves neonatal growth, digestive function, and gut immunity relative to donor human milk and infant formula in preterm pigs. Am J Physiol-Gastrointest Liver Physiol 311(3):G480-G491

Reardon J (2017) The postgenomic condition. Ethics, justice \& knowledge after the genome. University of Chicago Press, Chicago

Rock MJ (2013) Pet bylaws and posthumanist health promotion: a case study of urban policy. Crit Public Health 23(2):201-212

Rock MJ, Degeling C, Blue G (2014) Toward stronger theory in critical public health: insights from debates surrounding posthumanism. Crit Public Health 24(3):337-348

Sangild PT, Thymann T, Schmidt et al. (2014) The preterm pig as a model in pediatric gastroenterology. J Anim Sci 91(10):4713-4729

Schrader A (2015) Abyssal intimacies and temporalities of care: how (not) to care about deformed leaf bugs in the aftermath of Chernobyl. Soc Stud Sci 45 (5):665-690

Sharp L (2014) The transplant imaginary: Mechanical hearts, animal parts, and moral thinking in highly experimental science. University of California Press, Berkely and Los Angeles

Sharp LA (2019) Animal ethos: the morality of human-animal encounters in experimental lab science. University of California Press, Berkeley

Shen RL, Thymann T, Østergaard MV et al. (2015) Early gradual feeding with bovine colostrum improves gut function and NEC resistance relative to infant formula in preterm pigs. Am J Physiol-Gastrointest Liver Physiol 309(5): G310-G323

Star SL, Griesemer JR (1989) Institutional ecology,'translations' and boundary bbjects: Amateurs and professionals in Berkeley's Museum of Vertebrate Zoology 1907-39. Soc Stud Sci 19(3):387-420

Støy ACF, Heegaard PM, Thymann T et al. (2014) Bovine colostrum improves intestinal function following formula-induced gut inflammation in preterm pigs. Clin Nutr 33(2):322-329

Svendsen MN (2011) Articulating potentiality: Notes on the delineation of the blank figure in human embryonic stem cell Research. Cult Anthropol 26 (3):414-437

Svendsen MN, Koch L (2013) Potentializing the research piglet in experimental neonatal research. Curr Anthropol 54(7):118-128

Svendsen MN (2015) Selective reproduction: Social and temporal imaginaries for negotiating the value of life in human and animal neonates. Med Anthropol Q 29(2):178-195. https://doi.org/10.1111/maq.12149

Svendsen MN (2016) The spatial arrangements of making research piglets into resources for translational medicine. In: Bjørkdahl K, Druglitrø T (eds.) Animal housing and human-animal relations: politics, practices and infrastructures. Routledge Animal Studies Series. Buller H (ed), London and New York

Svendsen MN (2017) Pigs in public health. Crit Public Health 27(3):384-390. https://doi.org/10.1080/09581596.2017.1282155
Svendsen MN (2020) Pig-human relations in neonatology: knowing and unknowing in a multi-species collaborative. In: Seeberg J, Meinert L, Roepstorff A (eds) Biosocial Worlds. UCL Press, London

Swindle MM, Makin A, Herron AJ et al. (2012) Swine as models in biomedical research and toxicology testing. Vet Pathol 49(2):344-356

Taussig M (1999) Defacement: public secrecy and the labor of the negative. Stanford University Press, Stanford

Taussig KS, Hoeyer K, Helmreich S (2013) The anthropology of potentiality in biomedicine. Curr Anthropol 54(S7):S3-S14. https://doi.org/10.1086/671401

Tsing AL (2015) The mushroom at the end of the world: On the possibility of life in the capitalist ruins. Princeton University Press, Princeton and Oxford

Wainwright SP, Williams C, Michael M et al. (2006) Ethical boundary-work in the embryonic stem cell laboratory. Socio Health Illn 28(6):732-748. https://doi. org/10.1111/j.1467-9566.2006.00465.x

\section{Acknowledgements}

Our sincere thanks to the research team in the pig laboratory and to the parents and health professionals in the NICU, all of whom invited us into their daily practices. Thank you, piglets for teaching us to care about nonhuman animals in public health. Thank you to the participants in the workshop with Lenore Manderson in Copenhagen in June 2019 For intellectual inspiration, we are grateful to Clémence Pinél who commented on an earlier version of this article. Thank you to Iben M. Gjødsbøl and Laura E. Navne for continuous support and inspiration and to the entire MeInWe team. Finally, we acknowledge the support from the research platform NEOMUNE Centre and The Carlsberg Foundation (Grant number CF17-0016)

\section{Competing interests}

The authors declare no competing interests.

\section{Additional information}

Correspondence and requests for materials should be addressed to M.S.D.

Reprints and permission information is available at http://www.nature.com/reprints

Publisher's note Springer Nature remains neutral with regard to jurisdictional claims in published maps and institutional affiliations.

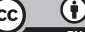

Open Access This article is licensed under a Creative Commons Attribution 4.0 International License, which permits use, sharing, adaptation, distribution and reproduction in any medium or format, as long as you give appropriate credit to the original author(s) and the source, provide a link to the Creative Commons license, and indicate if changes were made. The images or other third party material in this article are included in the article's Creative Commons license, unless indicated otherwise in a credit line to the material. If material is not included in the article's Creative Commons license and your intended use is not permitted by statutory regulation or exceeds the permitted use, you will need to obtain permission directly from the copyright holder. To view a copy of this license, visit http://creativecommons.org/ licenses/by/4.0/

(C) The Author(s) 2020 